\title{
Zwölf Jahre - Bilanz und Ausblick
}

\author{
Die Zahl Zwölf hat in Mathematik, Kultur und Gesellschaft eine besondere Bedeutung: Man den- \\ ke nur an die zwölf Monate des Jahres und die zwölf Stunden des Tages, die zwölf Stämme Isra- \\ els und die zwölf Apostel, die Zwölftonmusik und "Die zwölf Geschworenen“. Die \\ Vertragszahnärzteschaft lebt inzwischen nahezu zwölf Jahre mit der Hauptamtlichkeit der Vor- \\ stände von KZV und KZBV.
}

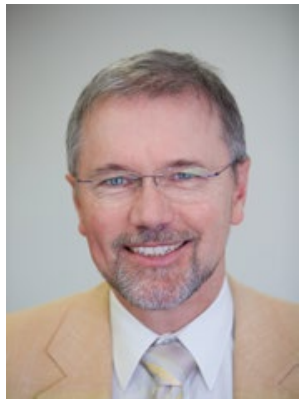

Dr. Joachim Hüttmann
Die Zahnärzteschaft hatte im Vorfeld der Verabschiedung des Gesetzes zur Modernisierung der Gesetzlichen Krankenversicherung (GMG) vehement gegen die Beseitigung der bis dahin ehrenamtlichen Strukturen gekämpft.

Man wollte sich nicht zum Handlager der von Ulla Schmidt und Angela Merkel gewollten Staatsmedizin machen lassen. Begründet und durchgesetzt wurde die Änderung damals mit dem Argument, dass die Selbstverwaltung „professionalisiert" und „Waffengleichheit“ mit den Kassenvorständen hergestellt werden müsse - auch gegen den Willen der Betroffenen. In der Folge gab es innerzahnärztlich heftige Auseinandersetzungen um die Frage: mitmachen oder verweigern? Das führte in einigen KZV-Bereichen zum Verlust der bisherigen Freiverbandsdominanz.

Hauptamtlichkeit kann man verordnen - Kompetenz nicht. Geführt wurden die „neuen“ KZVen fortan überwiegend von den bisher ehrenamtlich Tätigen, die nun per Gesetz zu „Profis“ werden sollten - und es dann auch werden mussten, weil sich die Arbeit nicht mehr „nach Feierabend“ erledigen ließ. Im günstigsten Fall retteten sie ihr Selbstverständnis als Freiberuflich-Selbstständige in die neue Tätigkeit hinüber. In den KZVen wurde versucht, auch strukturell Elemente des Ehrenamtes zu erhalten, teils gegen den Widerstand der Aufsichten. Es wurden Beiräte, Hauptausschüsse u. ä. Institutionen eingerichtet, um die Aufsichts- und Einflussmöglichkeiten der Vertreterversammlung auf die Geschäftspolitik zu sichern. Manche KZVSatzungen schreiben ein Quorum von Zahnärzten in den Vorständen vor, manche Satzungen fordern sogar von den Vorständen, weiterhin zahnärztlich tätig zu sein. Andererseits ist die Saat der „Schmidt/Merkel-Agenda“ im Gesundheitswesen aber aufgegangen. Die Distanz zwischen der „zahnärztlichen Basis“ und den Vorständen musste sich zwangsläufig vergrößern. Das liegt zum einen an der immer komplizierter werdenden Materie in deren Folge zunehmend nichtzahnärztliche Fachleute Aufgaben in den Vorständen übernahmen. Das liegt aber auch an der Struktur selbst, die es kaum mehr möglich macht, als standespolitisch interessierter Kollege oder Kollegin in die Aufgabe „hineinzuwachsen“. Die Generation mit der Erfahrung ehemaliger Ehrenamtstätigkeit in Vorständen scheidet zum großen Teil aus - Zahnärzte/Innen mit Management-Fähigkeiten fallen nicht vom Himmel.

Erschwerend kommt hinzu, dass die Einflussnahme der staatlichen Aufsicht immer direkter und immer einschneidender geworden ist. Während einerseits die selbstständig geführte Praxis durch Wettbewerbsnachteile ins Abseits gedrängt wird, wird zugleich das System der Selbstverwaltung in der GKV grundsätzlich in Frage gestellt. Vorläufiger Höhepunkt: Mit einem „Gesetz zur Stärkung der Handlungsfähigkeit der Selbstverwaltung der Spitzenorganisationen in der Gesetzlichen Krankenversicherung" sollen die Institutionen der Selbstverwaltung noch stärker reglementiert und kontrolliert werden. Josef Hecken, Vorsitzender des Gemeinsamen Bundesausschusses (GBA), bezeichnete die Pläne als „Gesetz zur Unterhöhlung und Eliminierung der Selbstverwaltung in der GKV“. Auch wenn die letzten Entwürfe entschärft wurden - es gehört schon eine gehörige Portion Zynismus dazu, zunächst das Ehrenamt und damit die Beteiligung und Kontrollmöglichkeiten der Betroffenen drastisch zu beschneiden, um dann anschließend mangelnde Kontrolle zu beklagen und dafür nach mehr staatlicher Kontrolle und direktem staatlichem Einfluss zu rufen.

Das meint Dr. Joachim Hüttmann - DFZ-Chefredakteur

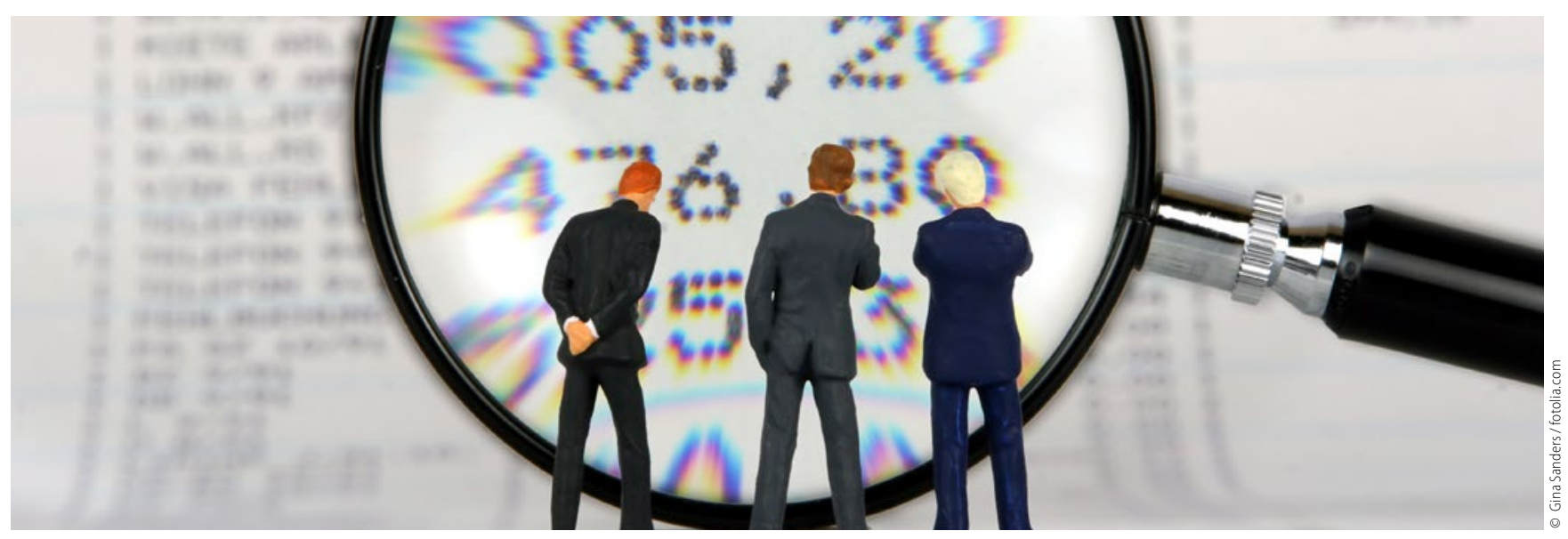

